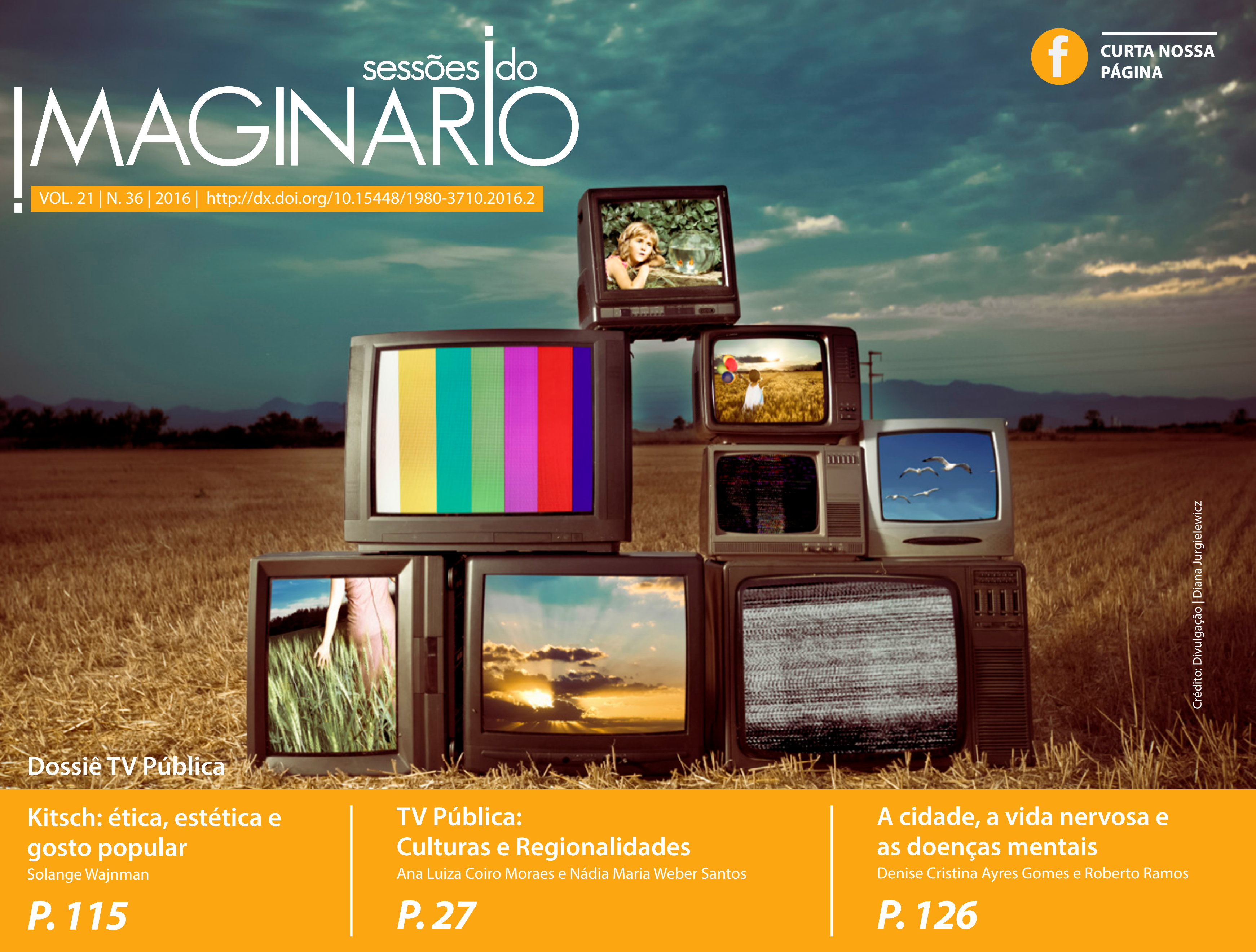




\section{TV Pública: culturas e regionalidades ${ }^{1}$}

\section{Public TV: cultures and regionalities}

\section{Ana Luiza Coiro Moraes ${ }^{2}[$ \\ Nádia Maria Weber Santos ${ }^{3}$}

\section{APRESENTAÇÃO DOSSIÊ}

27 PORTO ALEGRE | v. $21 \mid$ n. $36 \mid 2016$ | pp. 27-31 DOI: http://dx.doi.org /10.15448/1980-3710.2016.2.25698 Sessões do Imaginário
Neste texto, apresentamos o dossiê TV Pública: culturas e regionalidades, ora publicado na revista Sessões do Imaginário. Para tanto, organizamos a apresentação em quatro partes, além desta introdução. Na primeira delas, que denominamos Origens do dossiê: a pesquisa sobre o acervo audiovisual da TVE-RS, informamos, justamente, sobre o desenvolvimento do projeto de pesquisa Memória e Patrimônio da Fundação Piratini: o acervo audiovisual da TVE, que antecede a publicação deste dossiê. Trazemos à tona o processo de coleta e interpretação de dados do material encontrado no arquivo da TVE, bem como os conceitos e autores que fundamentaram a pesquisa. Por fim, descrevemos alguns dos produtos da pesquisa, que sinalizam a indagação que com ela surgiu, isto é, qual seria o estado da arte das investigações brasileiras acerca do tema televisão pública? Que outras culturas regionais se veriam representadas em arquivos audiovisuais pelo Brasil afora?

Tais perguntas geraram, dentre outros produtos da pesquisa, o presente dossiê, cuja descrição ganha espaço na segunda parte desta apresentação, que denominamos Contexto do dossiê: pesquisas brasileiras sobre TV Pública, Culturas e Regionalidades. É o momento do texto em que, resumidamente, apresentamos os artigos que compõem o dossiê, seus temas e objetos de pesquisa, suas referências teóricas e a discussão de seus resultados.

Concluindo, na parte do texto que denominamos Considerações finais sobre a relevância da pesquisa sobre TV Pública no Brasil, abordamos as contingências políticas atuais, dentre elas as medidas restritivas à atuação da Empresa Brasil de Comunicação (EBC), para reafirmar a importância de investigações que exponham, descrevam e interpretem as contingências das decisões políticas voltadas à televisão pública. 
Origens do dossiê: a pesquisa sobre o acervo audiovisual da TVE-RS

Este dossiê tem origem no projeto de pesquisa "Memória e Patrimônio da Fundação Piratini: o acervo audiovisual da TVE-RS", que se desenvolveu sob o amparo do edital Pesquisador Gaúcho (PQG) da Fundação de Amparo à Pesquisa do Estado do Rio Grande do Sul (FAPERGS). Tal acervo conta com cerca de 16.000 fitas em suportes diversos, dentre os quais, 4.300 fitas do tipo U-Matic, 5.000 fitas Super VHS e 4.250 fitas DVD PRO. A coleta de dados se deu no período de novembro/2014 a março/2016, no arquivo da emissora. Durante a pesquisa, foram analisadas 33 fitas U-Matic, 83 fitas Super VHS, onde encontramos fitas contendo imagens brutas, imagens editadas e programas da grade da emissora.

$\mathrm{E}$, para encaminhar o debate teórico de nossa pesquisa, cujo foco se localiza no conceito de memória cultural percebido a partir do acervo audiovisual de uma televisão pública, avaliamos, em primeiro lugar, a centralidade da cultura e o seu papel constitutivo em todos os aspectos da sociedade, que se dá, segundo Stuart Hall (1997, p.20), notadamente, a partir da segunda metade do século $X X$, quando é possível observar a "forma como a cultura penetra em cada recanto da vida social contemporânea, fazendo proliferar ambientes secundários, mediando tudo".

Martín-Barbero (1995) afirma que, em resposta à modernidade desencantada pelo triunfo da razão, a contemporaneidade presencia a um "reencantamento massmediatico". A televisão, especialmente, é um "lugar de visibilidade de mitos compartilhados", no sentido mais profundamente antropológico da palavra: "dos mitos que nos dão medo ou que nos tiram o medo, dos mitos que nos unem, dos mitos que nos protegem, dos mitos que nos salvam, dos mitos que dão sentido à pobre vida da maioria de nós..." (Martín-Barbero, 1995, p. 78).

Williams (2011, p. 23-24) estabelece uma relação dialética entre tecnologia e sociedade, e, mantendo a premissa fundante de que "a televisão foi inventada como resultado de investigação científica e tecnológica", confere alcance epistemológico à ideia de que este meio "alterou o mundo em que vivemos". Ele constata a crucial influência da televisão no modo de veiculação das notícias e do entretenimento, mas também "nas formas de nos relacionarmos" e "em alguns dos processos centrais da vida familiar, cultural e social", ou seja, atesta o seu poder como meio de comunicação social. "A mídia é, ao mesmo tempo, uma parte crítica na infraestrutura material das sociedades modernas, e, também, um dos principais meios de circulação das ideias e imagens vigentes nestas sociedades", completa Hall (1997, p.17).

Especificamente quanto à necessidade de emissoras públicas, é novamente Martín-Barbero (2002) que convocamos: "a existência de meios públicos justifica-se pela necessidade de possibilitar alternativas de comunicação, que deem entrada a todas aquelas exigências culturais que não cabem nos parâmetros do mercado, sejam elas provenientes das maiorias ou das minorias" (Martín-Barbero, 2002, p. 75).

E nessa circulação de ideias e de suas representações, centradas no arquivo audiovisual da TVE-RS, pensamos em seu acervo como fonte documental e imagética, que neste sentido se constitui em memória cultural da sociedade gaúcha.

A memória cultural, postula Assmann (2011), baseia-se em elementos simbólicos e sensíveis que compartilham sentidos, é transmitida por formas simbólicas (culturais) incorporadas numa socie- dade, e se caracteriza pela durabilidade. A autora também reconhece a importância das imagens na transmissão da memória cultural, quando elas surgem, sobretudo, em "regiões não alcançadas pelo processamento verbal" (Assmann, 2011, p.237). Ela ainda reitera a diferença que se dá na transmissão memorial por textos, pela via oral e pelas imagens: "O poder das imagens procura seus próprios caminhos de mediação" (Assmann, 2011, p. 244). E um arquivo, para a autora, não é somente um repositório de documentos do passado, é testemunha do passado e armazenador coletivo de conhecimentos. Trata-se de "um lugar onde o passado é construído e produzido", construção, esta, codeterminada por interesses sociais, culturais, políticos e também pelos meios de comunicação e pelas técnicas de registros (Assmann, 2011, pp. 25-26).

Munidas desse referencial teórico, os principais resultados que a pesquisa Memória e Patrimônio da Fundação Piratini: o acervo audiovisual da TVE-RS atingiu estão ligados à visualização e análise de fitas que contêm temas relacionados ao cenário e personalidades políticas nacionais e regionais, como as informações a respeito do declínio do Regime Militar no Brasil, dos processos para eleições diretas e a repercussão de lutas por direitos civis pautadas por movimentos sociais. Dentre uma grande quantidade de imagens representativas do estado, que incluem desde as cidades e seu desenvolvimento, passando por paisagens naturais, pelos símbolos culturais até a própria população sul rio-grandense, foi possível constatar a formulação de grades de programação com forte viés cultural, distribuídas em programas da TVE-RS como Radar e Estação Cultura, por exemplo. 
Em suma, trata-se de narrativas memoriais e culturais dos últimos 40 anos da primeira televisão pública do Rio Grande do Sul, cujo acervo audiovisual pode ser considerado como "consciência histórica" não só de suas diversas administrações (Bellotto, 2006), mas também de todos aqueles que partilharam o fazer das programações, de todos os gêneros, apresentando e reapresentando a identidade gaúcha. Neste sentido, comportam e se constituem em memória cultural.

Pensar esse acervo audiovisual em termos epistemológicos - que relaciona imagem, memória e televisão pública na dialética entre tecnologia, usos culturais e sociais dos últimos 40 anos da história cultural do Rio Grande do Sul - tornou-se, assim, um fator relevante e imprescindível para a memória da sociedade gaúcha.

Contudo, ao trabalhar com o acervo audiovisual da TVE-RS, constatamos a necessidade de incluir neste debate as emissoras públicas brasileiras em suas diferentes manifestações regionais, veiculando a diversidade cultural do país. Disso surgiu uma chamada de trabalhos que resultou no livro TVs Públicas: memórias de arquivos audiovisuais e neste dossiê, TV Pública, Culturas e Regionalidades.

\section{Contexto do dossiê: pesquisas}

brasileiras sobre TV pública, culturas

e regionalidades

O artigo de Ana Paula Oliveira remonta aos anos 1970, quando Vladimir Herzog dirigiu o telejornal Hora da Notícia, veiculado pela TV Cultura de São Paulo. A autora traz em seu texto a memória do assassinato brutal de Vladimir Herzog, perpetrado pela ditadura militar em 25 de outubro de 1975, que, ironicamente, desencadeou uma reação que foi determinante para o início da derrocada do próprio regime.
Além disso, o texto resgata a memória do telejornal, tendo como foco a sua discursividade, que dialoga com a linguagem cinematográfica, segundo a autora, levando à reflexão sobre as possibilidades de linguagem num telejornal de uma TV pública.

A primeira televisão educativa do Piauí é o tema do artigo de Diego Lopes da Silva Alves e Ana Regina Barros Rêgo Leal, que buscam em Pollak (1992) os três elementos constitutivos da memória: os acontecimentos, as personagens e os lugares, para reconhecer na histórica troca de nomes da emissora TV Educativa do Piauí, de 1985 a 1987 e depois de 1991 a 1995; TV Piauí, de 1995 a 2003; e TV Antares, de 1987 a 1991 e depois de 2003 até hoje —, ao mesmo tempo, conteúdos com as finalidades culturais e educativas previstas em sua concessão e a falta de uma identidade institucional, em grande parte pelo uso da emissora como meio de promoção política.

Fabiana da Costa Pereira e Maria Ivete Trevisan Fossá convocam o aporte teórico em torno do conceito de comunicação comunitária, acentuando o caráter de democratização da comunicação promovido por este tipo de emissora, não apenas provendo aos cidadãos um espaço de fala, mas posicionando-os como produtores e gestores dos veículos comunitários. Seu objeto de estudo é a TV Comunitária - TV Santa Maria, que permanece no ar 24 horas por dia, e apresenta uma grade de programação variada, cujos protagonistas são os artistas locais, o esporte amador e as notícias das comunidades.

Aline Lopes, Felipe Peres Calheiros e Patrícia Horta Alves lançam mão do conceito de comunicação pública como sistema de radiodifusão, associado a lei complementar 11.652/08, para estudarem a Semana de Comunicação Pública de Pernambuco, realizada desde
2013 pelo Núcleo de TV e Rádios Universitárias (NTVRU) da Universidade Federal de Pernambuco (UFPE). $O$ texto indica as redes educacionais que o evento promove, sobretudo em parcerias com cursos de comunicação social de Recife, Olinda e Caruaru, circulando entre profissionais, professores e estudantes.

Priscila Eugenia Trevisan Cestari e Ary José Rocco Jr. sugerem a TV pública como alternativa às emissoras comerciais para a transmissão de eventos esportivos que não encontram espaço na mídia comercial. Para tanto, eles analisam a inclusão de programas e transmissões esportivas na grade de programação de emissoras como a TV Cultura-SP e a TV Brasil.

Vitor Belém, Amálio Pinheiro e Fernando Moreira contextualizam conceitos de jornalismo público ao analisar o telejornal Conexão Aperipê, exibido pela Aperipê TV, emissora vinculada ao governo de Sergipe e retransmissora da programação da TV Brasil, cujo lema é "Educação, Cultura e Jornalismo Cidadão". Para os autores, compreender a prática do jornalismo público no âmbito do telejornalismo local é essencial para se verificar se tal prática atua (ou não) como ferramenta de fortalecimento da cidadania.

Ivonete da Silva Lopes aponta a reorganização da comunicação pública brasileira, que se deu com a constituição da Empresa Brasil de Comunicação (EBC), em 2007, e debate um dos princípios constitutivos da radiodifusão pública - a universalidade de acesso. A autora assinala as dificuldades encontradas pela TV Brasil para formar uma rede nacional de televisão pública na Região Sul e examina, dentre outros dados, os critérios para as outorgas educativas do governo federal, destacando que a região possui 28 TVs educativas (quantidade que é menor apenas do que a da região Sudeste), mas somente quatro de- 
las integram a rede pública liderada pela TV Brasil.

A leitura desses textos reafirma que as emissoras públicas têm significado político, ético e histórico, pois a televisão, ao produzir imagens, ao guardá-las e no trabalho ativo de preservá-las, faz de seus arquivos espaços de memória, locus privilegiado da memória coletiva e cultural ao mesmo tempo. Resgatar imagens televisivas, ou fragmentos delas, torna seus arquivos imprescindíveis para a memória cultural da sociedade brasileira, em seus instantes de verdade e na sua identidade (Pollak, 1992).

\section{Considerações finais sobre a relevância} da pesquisa sobre TV púlblica no Brasil

A leitura dos textos deste dossiê se constitui, ainda, num sinal de alerta para o rumo das políticas públicas relacionadas às televisões públicas, atualmente. $\mathrm{E}$ a este alerta se somam iniciativas como o Movimento para Preservação da TVE/FM Cultura, o Eu quero a TV Cultura Viva!, a Frente em defesa da EBC e da Comunicação Pública ${ }^{4}$, bem como alguns setores da imprensa, como a jornalista Tereza Cruvinel (2016), que afirma: "Não se pode mais chamar a TV Brasil de TV pública. É triste mas é a verdade. Com a extinção do Conselho Curador, do mandato do presidente da EBC e o fim das garantias de independência, será uma TV governamental". Também a revista Carta Capital se posicionou quanto às medidas governamentais envolvendo a Empresa Brasil de Comunicação:

Em 19 de fevereiro de 2008, o então deputado federal Michel Temer foi um dos 336 parlamentares que votaram a favor da Medida Provisória 398/2007. [...] Mais do que uma emissora, a EBC representou a época o cumprimento de um dispositivo da Constituição brasileira, a regulamentação da comunicação pública, que não pode ser confundida com uma emissora estatal. Passados oito anos, o agora presidente Temer resolveu com uma canetada desmontar os principais mecanismos de independência da EBC que ele mesmo aprovou no passado (Truffi, 2016, s/p.).

Dessa forma, reiteramos que os arquivos audiovisuais das televisões públicas devem ser considerados bens culturais imagéticos da sociedade brasileira e, por isso, merecem atenção e disposição tanto de órgãos governamentais como de instituições de ensino e pesquisa, a fim de que este potencial patrimônio possa ser reorganizado em seus arquivos, salvaguardados da destruição do tempo, bem como valorizados e divulgados de forma mais ampla para a sociedade.

Assim, agradecendo aos editores da revista a oportunidade e aos autores a confiança em nos entregarem seus textos, apresentamos ao público este dossiê, composto por artigos cujas reflexões se dirigem ao papel das TVs públicas na promoção da cultura, especialmente no que diz respeito às culturas regionais. Trata-se de pesquisas sobre o campo das televisões públicas, que contemplam temas ligados a seus regimes de gestão e de acessibilidade, a seus recursos tecnológicos, à formação de redes educativas, a paradigmas jornalísticos, seleção e manutenção de grades de programação, questões de identidade cultural e representação dos poderes públicos a que se vinculam, dentre outros temas que remetem, sobretudo, ao seu estatuto de dispositivo tecnológico que integra, configura/reconfigura o espaço público e que dá conta da abrangência territorial testemunhada por meio de arquivos audiovisuais.

\section{Referências}

ASSMANN, Aleida. Espaços da Recordação: formas e transformações da Memória Cultural. Campinas: Editora da UNICAMP, 2011.

CRUVINEL, Tereza. TV Brasil deixa de ser pública e vai retransmitir TV Cultura. Jornal Digital Brasil 247, 19/09/2016. Disponível em http://www.brasil247. $\mathrm{com} / \mathrm{pt} / \mathrm{blog} /$ terezacruvinel/256057/TV-Brasil-deixa-de-ser-p\%C3\%BAblica-e-vai-retransmitir-TV-Cultura.htm. Acesso em: 20 out. 2016

HALL, Stuart. A centralidade da cultura: notas sobre as revoluções culturais de nosso tempo. Educação e Realidade, Porto Alegre, v. 22, nº. 2, jul./dez. 1997, p. 15-46.

MARTÍN-BARBERO, Jesús. Globalización comunicacional y descentramiento cultural. Diálogos de la comunicación, 47, 1997, p. 27-41.

MARTÍN-BARBERO, Jesús. Televisão pública, televisão cultural: entre a renovação e a invenção. In RINCÓN, Omar (org.) Televisão pública: do consumidor ao cidadão. São Paulo: Friedrich Ebert Stiftung, 2002, p. 41-79.

POLLACK, Michael. Memória e identidade social. Estudos Históricos, v. 5, n. 10, 1992, p. 200-212.

TRUFFI, Renato. EBC, a nova obsessão de Temer. Revista Carta Capital, 16/09/2016. Disponível em http://www.cartacapital.com.br/revista/918/ebc-anova-obsessao-de-temer. Acesso em: 20 out. 2016. 
WILLIAMS, Raymond. Televisión: tecnología y forma cultural. Buenos Aires: Paidós, 2011.

\section{Notas}

1 Processo número 2353-2551/14-0, sob apoio do Edital 02/2014 Pesquisador Gaúcho (PQG) da Fundação de Amparo à Pesquisa do Estado do Rio Grande do Sul (FAPERGS).

2 Doutora em Comunicação Social pela Pontifícia Universidade Católica do Rio Grande do Sul (PUCRS). Professora do Programa de Pós-Graduação da Faculdade Cásper Líbero (Av. Paulista, 900 Bela Vista, São Paulo - SP, 01310-100). E-mail: anacoiro@gmail.com.

3 Doutora em História pela Universidade Federal do Rio Grande do Sul (UFRGS). Pesquisadora do Instituto Histórico e Geográfico do Rio Grande do Sul (IHGRGS - R. Riachuelo, 1317 - Centro, Porto Alegre -RS, 90010-241).E-mail: nnmmws@gmail.com.

4 Os movimentos têm perfis no Facebook, disponíveis, respectivamente, em https://www.facebook. com/groups/793536650682242, https://www.facebook.com/search/top/?q=eu\%20quero\%20a\%20 tv\%20cultura\%20viva! e https://www.facebook. $\mathrm{com} /$ search/top/?q=frente\%20em\%20defesa\%20 da\%20ebc\%20e\%20da\%20comunica\%C3\%A7\%C3\%A3o\%20p\%C3\%BAblica. 